\title{
Analisis Comment To Likes Ratio Youtube Pada 5 Youtuber Indonesia Dengan Subscriber Terbanyak
}

\author{
Nena Febby Arsiana \\ nenafebby@gmail.com
}

\begin{abstract}
Youtube is the number 1 video sharing website in the world. Youtube is an application that provides information in the form of videos. Uploaded videos can also be seen by the whole world. There are various kinds of video clips uploaded by various groups of users. Starting from tutorials, music clips, movie trailers, educational videos, short films, television films, video blogs, and so on. If you look at its history, Youtube was founded in February 2005. According to research results, 92 percent of Indonesian users say YouTube is their first destination. when looking for video content. The large number of active Youtube users in Indonesia can certainly provide opportunities for Indonesian Youtubers to make the Youtube platform a social media marketing platform. As for the 5 Indonesian Youtubers with the Most Subscribers who use Youtube as a marketing platform, namely: Atta Halilintar, Ricis Official,Jes No Limit,Rans Entertainment and Baim Paula. The purpose of this study is to determine the credibility value of the performance of the Youtube account of 5 Indonesian YouTubers with the Most Subscribers. This study uses a qualitative exploratory method. The results of this study indicate that YouTuber Baim Paula is ranked first and has good channel performance credibility.
\end{abstract}

\begin{abstract}
ABSTRAK
Youtube merupakan situs web berbagi video nomor 1 di dunia.Youtube adalah salah satu aplikasi yang memberi informasi berupa video-video. video yang di unggah juga dapat dilihat oleh seluruh dunia. Ada berbagai macam video klip yang diunggah oleh berbagai kalangan pengguna. Mulai dari tutorial, klip musik, trailer film, video edukasi, film pendek, film televisi, video blog, dan sebagainya.Jika dilihat dari sejarahnya, Youtube berdiri sejak Febuari 2005. Menurut hasil riset, 92 persen pengguna Indonesia menyatakan YouTube adalah tujuan pertama mereka ketika mencari konten video.Banyaknya jumlah pengguna Youtube yang aktif di indoneisa tentu dapat memberikan peluang bagi Youtuber Indonesia untuk menjadikan platform Youtube sebagai platform social media marketing.Adapun 5 Youtuber Indonesia Dengan Subscriber Terbanyak yang memanfaatkan Youtube sebagai platform marketing,yaitu : Atta Halilintar,Ricis Official,Jes No Limit,Rans Entertainment dan Baim Paula. Tujuan dari penelitian ini yaitu mengetahui nilai kredibillitas dari performa akun Youtube 5 YouTuber Indonesia Dengan Subscriber Terbanyak. Penelitian ini menggunakan metode ekploratif Kualitatif. Hasil dari penelitian ini menunjukkan bahwa youtuber Baim Paula mendapatkan peringkat pertama dan memiliki kredibilitas performa channel yang baik.
\end{abstract}

Keyword :Credibility Account TikTok ;Social media marketing; social media Youtube;Comment to Likes Ratio:Youtuber Indonesia 


\section{PENDAHULUAN}

Perkembangan internet berkembang dengan pesat sesuai dengan pertumbuhan perkembangan situasi sosial yang ada. Salah satu bentuknya adalah Situs Video YouTube. Walau dalam perkembangannya Situs Video YouTube tidak lagi hanya digunakan lagi sebagai media untuk mengunggah dan membagikan video-video pribadi kepada rekan-rekan terdekat saja, tetapi lebih dari itu. Melalui pengumpulan informasi sumber-sumber yang ada dan mengolahnya kepada bentuk sebuah analisis konten materi Video, telah dihasilkan berbagai gambaran bagaimana Situs Video YouTube secara spesifik digunakan oleh para penggunanya sesuai dengan tujuan dan seleranya (Chandra 2017).

Media Sosial menggunakan teknologi berbasis web yang mengubah komunikasi menjadi dialog interaktif. Beberapa jenis situs media sosial populer saat ini antara lain Instagram, Twitter, Facebook, TikTok, hingga Youtube.Definisi lain dari media sosial juga dijelaskan oleh Van Dijk, yang mengungkapkan bahwa media sosial adalah platform media yang memfokuskan pada eksistensi pengguna yang memfasilitasi mereka dalam beraktivitas maupun berkolaborasi. ("Mengenal Fungsi Media Sosial, Berikut Pengertian Dan Jenisnya Halaman 2 | Merdeka.com" n.d.)

Ada berbagai macam video klip yang diunggah oleh berbagai kalangan pengguna. Mulai dari tutorial, klip musik, trailer film, video edukasi, film pendek, film televisi, video blog, dan sebagainya.Jika dilihat dari sejarahnya, Youtube berdiri sejak Febuari 2005. Founder youtube, Jawed Karim, Steven Chen, serta Chad Hurley kemudian mendirikan markas besar Youtube di San Bruno, California, Amerika Serikat ("Pengertian Youtube, Manfaat Dan Fitur-Fitur Menarik Di Youtube" n.d.).di Indonesia cukup banyak youtuber Indonesia yang terkenal dan memiliki banyak subscriber,Adapun 5 YouTuber Indonesia Dengan Subscriber Terbanyak,diantaranya yaitu : Atta Halilintar,Ricis Official,Jess No limit,Rans Entertainment,Baim Paula ("5 YouTuber Indonesia Dengan Subscriber Terbanyak") ("5 YouTuber Indonesia Dengan Subscriber Terbanyak, Didominasi Artis - Tabloidbintang.com” n.d.).

Penelitian ini menggunakan metode ekploratif Kualitatif ,dan akan menghitung menggunakan rasio-rasio yang ada pada Youtube pada penelitian (Hendika Permana 2021) menjelaskan bahwa terdapat 10 rasio yang ada pada sosial media Youtube dan relevan digunakan sebagai media ukur kredibilitas channel yang ada.Penelitian ini hanya berfokus untuk menghitung kredibilitas Comment to Likes Ratio pada 5 YouTuber Indonesia Dengan Subscriber Terbanyak,diantaranya yaitu : Atta Hlilintar,Ricis Official,Jess No Limit,Rans Entertainment dan Baim Paula ("5 YouTuber Indonesia Dengan Subscriber Terbanyak, Didominasi Artis - Tabloidbintang.com" n.d.).Tujuan penelitian ini adalah mengetahui kredibilitas performa dari akun Youtube 5 YouTuber Indonesia Dengan Subscriber Terbanyak menggunakan Comment to Likes Ratio.

\section{TIJNJAUAN PUSTAKA}

Ketertarikan masyarakat dalam kemudahan akses yang diberikan oleh perangkat teknologi smartphone membuat media televisi tergeser, terbukti dengan pertumbuhan pengguna internet di Indonesia dan Munculnya SmartTV. Dan para pelaku industri Televisi yang semakin banyak merambah platform internet Youtube. Dengan munculnya teknologi SmartTV menandakan perangkat televisipun menyediakan layanan untuk memutar platform internet Youtube. Para pelaku industri televisi mengembangkan area untuk meraih penonton ke media sosial Youtube, 
hal ini diakibatkan karena masyarakat saat ini sangat butuh fleksibilitas waktu dan hiburan sesuai dengan keinginannya (Safitri 2021).

YouTube menyediakan forum bagi orang-orang untuk saling berhubungan, memberikan informasi, dan menginspirasi orang lain di seluruh dunia, serta bertindak sebagai platform distribusi bagi pembuat konten asli dan pengiklan, baik yang besar maupun kecil. YouTube merupakan salah satu perusahaan milik Google (David, Sondakh, and Harilama 2017).

Kehadiran YouTube membawa pengaruh luar biasa kepada masyarakat, khususnya masyarakat yang memiliki gairah di bidang pembuatan video, mulai dari film pendek, dokumenter, hingga video blog, tetapi tidak memiliki ,lahan "untuk mempublikasikan karyanya”. YouTube mudah dipergunakan, tidak memerlukan biaya tinggi, dan dapat diakses dimanapun, tentunya dengan gadget yang kompatibel. Hal itu membuat pembuat video amatir dapat dengan bebas mengunggah konten-konten video mereka untuk dipublikasikan. Jika video mereka mendapat sambutan baik, jumlah viewers akan bertambah. Viewers banyak akan mengundang pengiklan untuk memasang iklan dalam video-video mereka selanjutnya. Senada dengan televisi, konten program televisi yang disukai masyarakat, dalam hal ini ratingnya tinggi, akan menarik pengiklan secara otomatis (David, Sondakh, and Harilama 2017).

Kebutuhan akan mobilitas yang tinggi dan kebutuhan hiburan untuk masyarakat juga memaksa para pelaku industri televisi untuk mengunggah produk mereka ke media internet seperti youtube,agar para penonton dapat menikmati layanan mereka dan mendapatkan penghasilan dari layanan iklan youtube.telah diunggah bersifat gratis ,dan juga memungkinkan mendapatkan bayaran(monetize) dari layanan Google Adsense dengan mengizinkan iklan untuk diputar pada video yang diunggah,namun pada 2019 seluruh video yang diputar pada media youtube sudah otomatis menampilkan iklan , untuk menonton video tanpa iklan di Youtube,para penonton harus berlangganan layanan bebas iklan pada platform ini (Safitri 2021).

\section{METODE PENELITIAN}

Penelitian ini menggunakan metode ekploratif Kualitatif untuk mengetahui kredibilitas dari performa akun Youtube 5 YouTuber Indonesia Dengan Subscriber Terbanyak. Penelitian tipe eksploratif, bertujuan memperdalam pengetahuan dan mencari ide-ide baru mengenai suatu gejala tertentu, menggambarkan fenomena sosial, dan menjelaskan bagaimana terjadinya suatu fenomena sosial untuk merumuskan masalah secara lebih terperinci atau mengembangkan hipotesis bukan menguji hipotesis .(Mudjiyanto 2018)

Tujuan dari penelitian ini yaitu mengetahui nilai kredibillitas dari performa akun Youtube 5 YouTuber Indonesia Dengan Subscriber Terbanyak. Ada beberapa langkah yang harus dilakukan dalam penelitian ini, sehingga mampu menemukan peringkat pertama akun Youtube YouTuber Indonesia Dengan Subscriber Terbanyak yang memiliki performa terbaik. Langkah-langkah yang dilakukan pada penelitian ini, diantaranya yaitu :

\section{Melakukan Eksplorasi Pada Website Untuk Menentukan Objek yang Akan Dianalisa.}

Eksplorasi ini dilakukan pada beberapa halaman website yang menyediakan informasi mengenai objek yang akan di teliti. Setelah eksplorasi selesai dilakukan, sehingga ditemukan nama-nama YouTuber Indonesia Dengan Subscriber Terbanyak yang akan 
dijadikan objek analisa. Setelah melakukan eksplorasi pada halaman website, maka langkah selanjutnya yaitu mencari nama akun Youtube dari masing-masing Youtuber Indonesia. Pastikan semua Youtuber memiliki akun pada aplikasi sosial media Youtube.

\section{Menghitung Nilai Rata-Rata Variable Dari 5 YouTuber Indonesia Dengan Subscriber Terbanyak}

Pada langkah ini, peneliti menghitung nilai variable comments dan variable likes. Variabel mencakup segala sesuatu yang ditetapkan untuk mendapatkan informasi mengenai hal tersebut hingga bisa ditarik kesimpulannya. Secara umum, variabel merupakan sesuatu yang beragam sehingga sifatnya dapat berubah-ubah, bermacam-macam, dan berbedabeda ("Variabel Penelitian: Pengertian, Jenis, Dan Contohnya | Kumparan.com" n.d.). Untuk menghitung nilai rata-rata dari variabel comments dan variabel Likes yaitu dengan cara mengambil minimal 10 postingan kemudian di hitung sehingga menemukan nilai rata-rata dari masing-masing variabel.

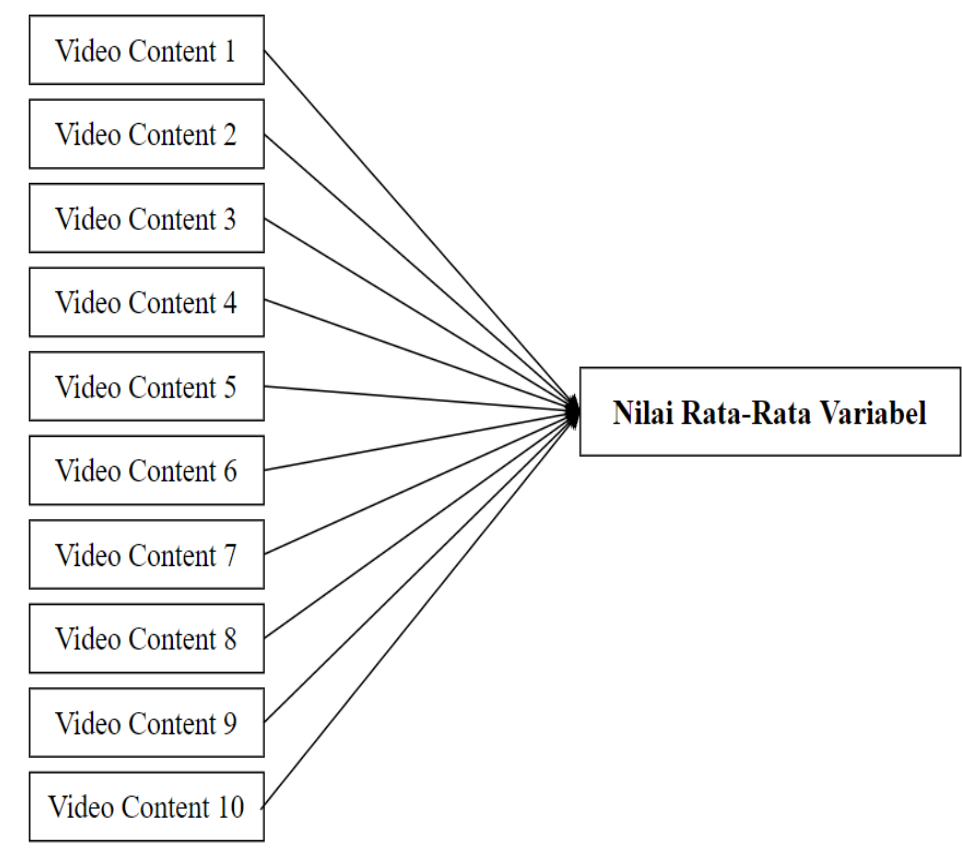

Gambar 1. Analisa Nilai Rata-Rata Variabel.

\section{Menghitung Nilai Kredibilitas Rasio}

Untuk menghitung nilai kredibilitas dari comments to likes ratio, peneliti menggunakan cara membagi nilai variabel pertama dengan nilai variabel kedua. Jika comments memiliki nilai 100 dan likes memiliki nilai 300, maka cara menghitungnya yaitu $100: 300$ $=0,3$. Dengan begitu nilai dari comments to likes ratio adalah 0,3 .

\section{Menentukan Peringkat Pada Akun TikTok}

Pada langkah terakhir yang dilakukan pada penelitian ini yaitu menentukan peringkat pada masing-masing rasio yang ada. Pada penentuan peringkat perlu melihat karakteristik dari rasio yang di teliti. Jika karakteristik rasio merupakan rendah, maka objek yang memiliki nilai terendah akan mendapatkan angka 5 dan objek yang memiliki nilai tertinggi akan mendapatkan angka 1. Namun jika rasio memiliki karakteritik tinggi maka objek yang mendapatkan nilai tinggi akan mendapatkan angka 5 dan objek yang 
mendapatkan nilai terendah akan mendapatkan angka 1. Setelah mendapatkan hasil kredibilitas ratio maka dapat disimpulkan objek yang mana mendapatkan peringkat 1 sampai dengan peringkat 5 .

\section{HASIL DAN PEMBAHASAN}

Akun Youtube dari 5 Youtuber Indonesia Dengan Subscriber Terbanyak,diantaranya :

\section{Atta Halilintar}

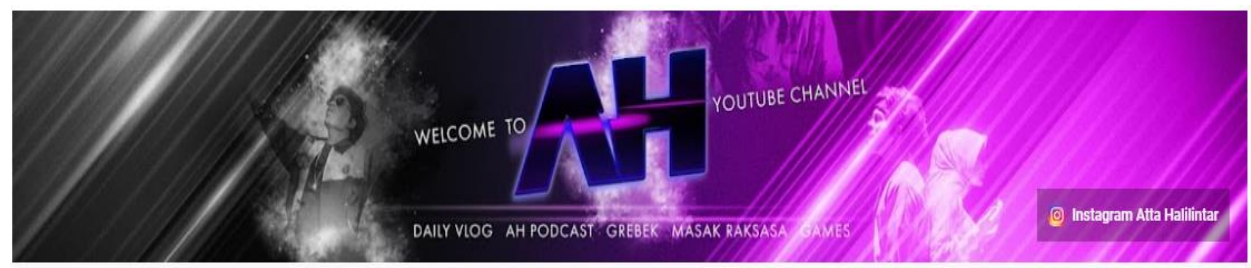

$\mathrm{AH} \odot$

$28 \mathrm{jt}$ subscriber

Gambar 1.Akun Youtube Atta Halilintar

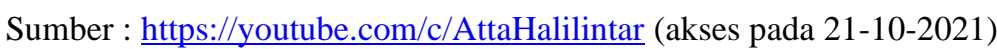

\section{Ricis Official}

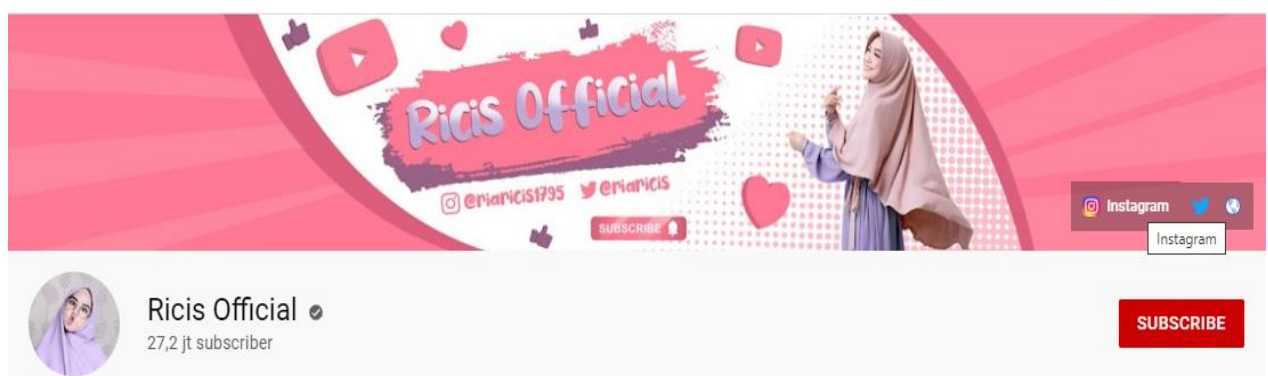

Gambar 2. Akun Youtube Ricis Official

Sumber : https://youtube.com/c/Ricisofficial1795 (akses pada 21-10-2021)

\section{Jess No Limit}

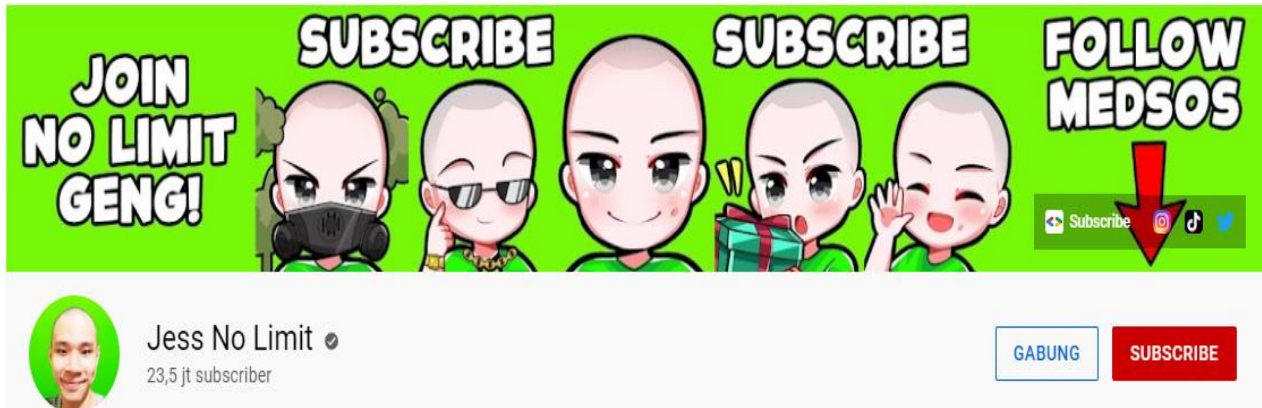

Gambar 3. Akun Youtube Jess No limit

Sumber : https://youtube.com/c/JessNoLimit (akses pada 21-10-2021) 


\section{Rans Entertainment}

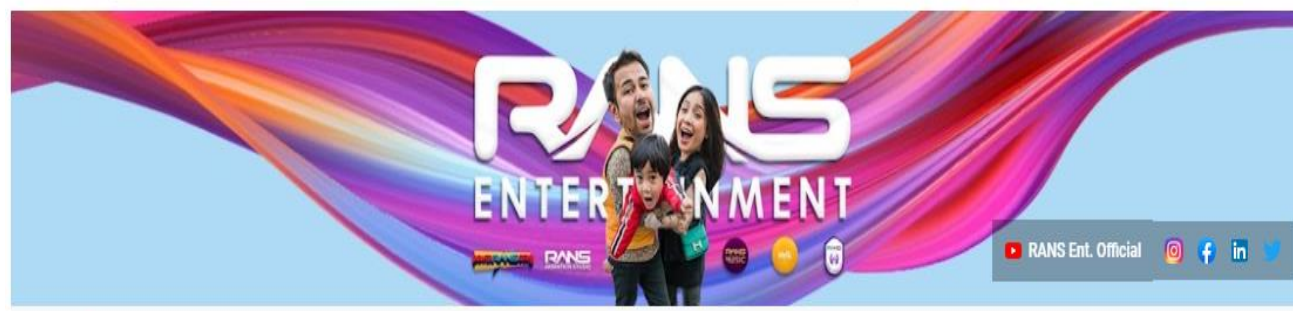

Rans Entertainment $\bullet$

21,8 jt subscriber

Gambar 4. Akun Youtube Rans Entertainment

Sumber : https://youtube.com/c/RansEntertainment (akses pada 21-10-21)

\section{Baim Paula}

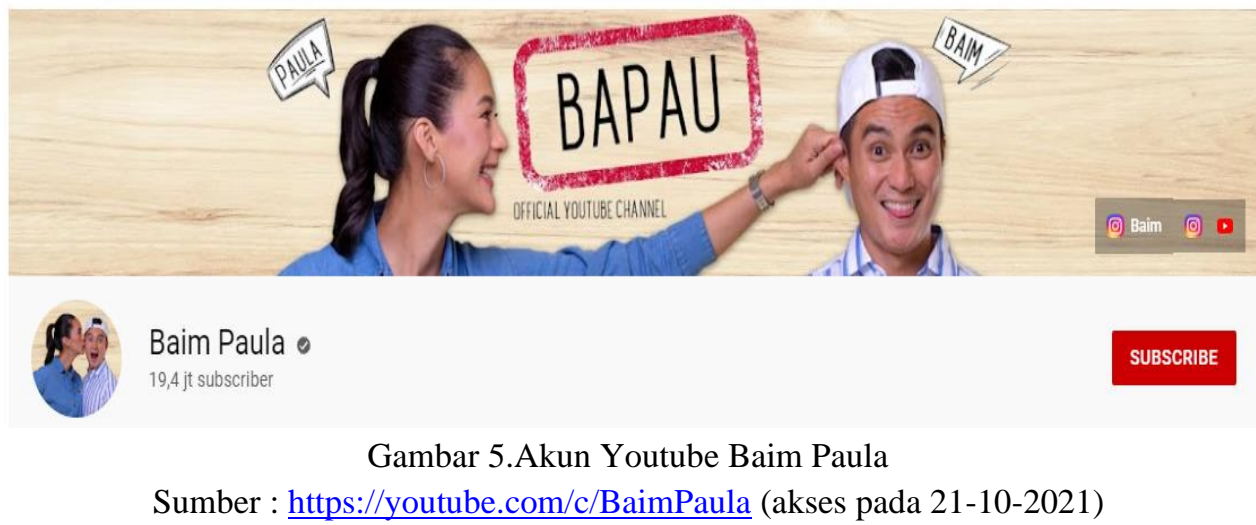

Dari kelima akun Youtube 5 Youtuber Indonesia Dengan Subscriber Terbanyak,Peneliti menemukan nilai dari masing-masing variabel yang ada untuk menghitung rasio Comment To Likes dari setiap akun.Pada akun Youtube memiliki 6 Variabel,yaitu :

1. Variabel Post

2. Variabel Subscriber

3. Variabel Likes

4. Variabel Dislike

5. Variabel Viewers

6. Variabel Comments

Dari keenam variabel tersebut peneliti hanya fokus untuk menemukan hasil dari 2 variabel,yaitu :

1. Comments

2. Likes

Dari kedua Variabel tersebut kemudian dianalisa sehingga menemukan nilai rata-rata dari variabel Comments dan variabel Likes. Untuk menghitung nilai rata -rata dari variabel comments dan variabel likes yaitu dengan cara mengambil minimal 10 postingan kemudian di hitung sehingga menemukan nilai rata-rata dari masing-masing variabel.Berikut merupakan tabel nilai 
rata-rata dari masing-masing akun youtube 5 youtuber Indonesia dengan subscriber terbanyak, yaitu :

Tabel 1. Analisa Nilai Rata-rata Nilai Variabel Comments dan likes akun Youtube Atta Halilintar

\begin{tabular}{|c|r|c|}
\hline No & Comment & \multicolumn{1}{l|}{ Likes } \\
\hline 1 & 3.800 & 29.000 \\
\hline 2 & 2.000 & 19.000 \\
\hline 3 & 3.300 & 32.000 \\
\hline 4 & 2.400 & 24.000 \\
\hline 5 & 4.600 & 48.000 \\
\hline 6 & 5.500 & 50.000 \\
\hline 7 & 5.800 & 55.000 \\
\hline 8 & 4.700 & 49.000 \\
\hline 9 & 5.600 & 90.000 \\
\hline 10 & 3.000 & 60.000 \\
\hline Total & $\mathbf{4 . 0 7 0}$ & $\mathbf{4 5 . 6 0 0}$ \\
\hline Sun
\end{tabular}

Sumber : Pengolahan Data Excel

Tabel 2. Analisa Nilai Rata-rata Nilai Variabel Comments dan likes akun Youtube Ricis Offical

\begin{tabular}{|c|r|r|}
\hline No & Comment & \multicolumn{1}{l|}{ Likes } \\
\hline 1 & 3.700 & 38.000 \\
\hline 2 & 6.200 & 58.000 \\
\hline 3 & 6.100 & 90.000 \\
\hline 4 & 4.600 & 84.000 \\
\hline 5 & 7.800 & 116.000 \\
\hline 6 & 7.100 & 105.000 \\
\hline 7 & 10.000 & 106.000 \\
\hline 8 & 7.000 & 109.000 \\
\hline 9 & 5.300 & 86.000 \\
\hline 10 & 6.400 & 89.000 \\
\hline Total & $\mathbf{6 . 4 2 0}$ & $\mathbf{8 8 . 1 0 0}$ \\
\hline
\end{tabular}

Sumber : Pengolahan Data Excel 
Tabel 3. Analisa Nilai Rata-rata Nilai Variabel Comments dan likes akun Youtube Jess No Limit

\begin{tabular}{|c|r|c|}
\hline No & Comment & Likes \\
\hline 1 & 1.800 & 15.000 \\
\hline 2 & 2.600 & 23.000 \\
\hline 3 & 1.700 & 20.000 \\
\hline 4 & 2.300 & 26.000 \\
\hline 5 & 1.600 & 16.000 \\
\hline 6 & 1.600 & 14.000 \\
\hline 7 & 1.300 & 13.000 \\
\hline 8 & 2.700 & 35.000 \\
\hline 9 & 1.900 & 16.000 \\
\hline 10 & 1.800 & 21.000 \\
\hline Total & $\mathbf{1 . 9 3 0}$ & $\mathbf{1 9 . 9 0 0}$ \\
\hline
\end{tabular}

Sumber : Pengolahan Data Excel

Tabel 4. Analisa Nilai Rata-rata Nilai Variabel Comments dan likes akun Youtube Rans Entertainment

\begin{tabular}{|c|r|r|}
\hline No & Comment & \multicolumn{1}{c|}{ Likes } \\
\hline 1 & 469 & 5.200 \\
\hline 2 & 803 & 22.000 \\
\hline 3 & 1.400 & 66.000 \\
\hline 4 & 1.000 & 12.000 \\
\hline 5 & 2.000 & 107.000 \\
\hline 6 & 1 & 55.000 \\
\hline 7 & 0 & 1.300 \\
\hline 8 & 0 & 2.200 \\
\hline 9 & 0 & 1.600 \\
\hline 10 & 0 & 4.200 \\
\hline Total & $\mathbf{5 6 7}$ & $\mathbf{2 7 . 6 5 0}$ \\
\hline
\end{tabular}

Sumber : Pengolahan Data Excel 
Tabel 5. Analisa Nilai Rata-rata Nilai Variabel Comments dan likes akun Youtube Baim Paula

\begin{tabular}{|c|c|c|}
\hline No & Comment & Likes \\
\hline 1 & 5.100 & 33.000 \\
\hline 2 & 113.000 & 141.000 \\
\hline 3 & 9.800 & 71.000 \\
\hline 4 & 30.000 & 123.000 \\
\hline 5 & 8.400 & 107.000 \\
\hline 6 & 10.000 & 216.000 \\
\hline 7 & 5.600 & 133.000 \\
\hline 8 & 37.000 & 95.000 \\
\hline 9 & 1.200 & 41.000 \\
\hline 10 & 2.500 & 92.000 \\
\hline Total & 22.260 & 105.200 \\
\hline
\end{tabular}

Setelah menghitung nilai rata-rata tersebut, maka akan menemukan hasil akhir nilai rata-rata dari variabel comments dan likes.

Tabel 6. Nilai Variabel Pada Akun Youtube 5 Youtuber Indonesia Dengan Subscriber Terbanyak

\begin{tabular}{|l|c|c|c|c|c|}
\hline Variabel & Atta Halilintar & $\begin{array}{c}\text { Ricis } \\
\text { Official }\end{array}$ & $\begin{array}{c}\text { Jess No } \\
\text { Limit }\end{array}$ & $\begin{array}{c}\text { Rans } \\
\text { Entertainment }\end{array}$ & Baim Paula \\
\hline Comment & 4.070 & 6.420 & 1.930 & 567 & 22.260 \\
\hline Likes & 45.600 & 88.100 & 19.900 & 27.650 & 105.200 \\
\hline
\end{tabular}

Pada Akun Youtube terdapat 10 rasio yang relevan digunakan untuk mengukur kredibilitas pada masing-masing akun.Namun pada penelitian kali ini hanya berfokus untuk menghitung Comment to Likes Ratio.Untuk menghitung kredibilitas dari masing-masing akun Youtube setiap Youtuber Indonesia,Peneliti menghitung dengan cara : Variabel 1 akan dibagi dengan Variabel 2,sehingga ditemukan hasil analisa dari rasio tersebut.

Tabel 7. Hasil Perhitungan Rasio Akun Youtube

\begin{tabular}{|c|c|c|c|c|c|c|}
\hline No & Ratio & $\begin{array}{c}\text { Atta } \\
\text { Halilintar }\end{array}$ & $\begin{array}{c}\text { Ricis } \\
\text { Official }\end{array}$ & $\begin{array}{c}\text { Jess No } \\
\text { Limit }\end{array}$ & $\begin{array}{c}\text { Rans } \\
\text { Entertainment }\end{array}$ & $\begin{array}{c}\text { Baim } \\
\text { Paula }\end{array}$ \\
\hline 1 & $\begin{array}{c}\text { Comment to } \\
\text { Likes ratio }\end{array}$ & 0,089254 & 0,072872 & 0,096985 & 0,020506 & 0,211597 \\
\hline
\end{tabular}


Comment to Likes Ratio memiliki karakteristik yang Tinggi,Artinya semakin tinggi nilai yang dihasilkan maka semakin baik kredibilitas dari performa akun tersebut.Untuk memberikan peringkat pada masing-masing akun youtuber,Peneliti memberikan angka 5 kepada youtuber yang mendapatkan nilai tertinggi dan angka 1 untuk akun youtuber yang mendapatkan nilai terendah.Berikut merupakan tabel urutan nilai yang dihasilkan oleh masing-masing akun youtube

Tabel 8. Niai Rasio akun Youtube 5 Youtuber Indonesia Dengan Subscriber Terbanyak

\begin{tabular}{|c|c|c|c|c|c|}
\hline & \multicolumn{5}{|c|}{ NILAI } \\
\cline { 2 - 6 } \multicolumn{1}{c|}{ RATIO } & $\begin{array}{c}\text { Atta } \\
\text { Halilintar }\end{array}$ & $\begin{array}{c}\text { Ricis } \\
\text { Official }\end{array}$ & $\begin{array}{c}\text { Jess No } \\
\text { Limit }\end{array}$ & Rans Entertainment & $\begin{array}{c}\text { Baim } \\
\text { Paula }\end{array}$ \\
\cline { 1 - 6 } Comment to & 3 & 2 & 4 & 1 & 5 \\
\hline Likes Ratio & 3 & & 1 & & \\
\hline
\end{tabular}

Sumber : Pengolahan Data Excel

Dari Tabel Nilai Rasio akun Youtube 5 Youtuber Indonesia Dengan Subscriber Terbanyak dapat disimpulkan bahwa Baim Paula mendapatkan nilai tertinggi untuk rasio Comment to Likes.Sedangkan akun Youtube Rans Entertainment mendapatkan nilai terendah untuk rasio ini.Jadi, pada penelitian ini Baim Paula memiliki kredibilitas performa yang lebih baik dibandingkan dengan akun youtuber lainnya.

\section{KESIMPULAN}

Tujuan dari Penelitian ini adalah mengetahui kredibilitas performa dari akun Youtube 5 Youtuber Indonesia Dengan Subscriber Terbanyak menggunakan Comment to Likes Ratio. 5 Youtuber Indonesia Dengan Subscriber Terbanyak tersebut diantaranya : Atta Halilintar,Ricis Official,Jess No Limit,Rans Entertainment,dan Baim Paula.Dari kelima akun youtuber tersebut dapat disimpulkan bahwa :

1. Peringkat pertama diraih oleh akun youtube Baim Paula dengan nilai tertinggi yaitu 0,211597

2. Peringkat kedua diraih oleh akun youtube Jess No Limit dengan nilai 0,096985

3. Peringkat ketiga diraih oleh akun youtube Atta Halilintar dengan nilai 0,089254

4. Peringkat keempat diraih oleh akun youtube Ricis Official dengan nilai 0,072872

5. Peringkat kelima diraih oleh akun youtube Rans Entertainment dengan nilai terendah yaitu 0,020506 


\section{DAFTAR PUSTAKA}

"5 YouTuber Indonesia Dengan Subscriber Terbanyak, Didominasi Artis - Tabloidbintang.com." n.d. Accessed October 29, 2021.

https://www.tabloidbintang.com/berita/polah/read/161409/5-youtuber-indonesia-dengansubscriber-terbanyak-didominasi-artis.

Chandra, Edy. 2017. "Youtube, Citra Media Informasi Interaktif Atau Media Penyampaian Aspirasi Pribadi.” Jurnal Muara Ilmu Sosial, Humaniora, Dan Seni 1 (2): 406-17.

David, Eribka Ruthellia, Mariam Sondakh, and Stefi Harilama. 2017. "Pengaruh Konten Vlog Dalam Youtube Terhadap Pembentukan Sikap Mahasiswa Ilmu Komunikasi Fakultas Ilmu Sosial Dan Politik Universitas Sam Ratulangi.” Acta Diurna Komunikasi 6 (1).

Hendika Permana, I Putu. 2021. “Analisis Rasio Pada Akun Youtube Untuk Penelitian Kualitatif Menggunakan Metode Ekploratif.” Jurnal Ilmiah Media Sisfo 15 (1): 40. https://doi.org/10.33998/mediasisfo.2021.15.1.970.

"Mengenal Fungsi Media Sosial, Berikut Pengertian Dan Jenisnya Halaman 2 | Merdeka.com." n.d. Accessed October 29, 2021. https://www.merdeka.com/jabar/mengenal-fungsi-mediasosial-berikut-pengertian-dan-jenisnya-kln.html?page $=2$.

Mudjiyanto, Bambang. 2018. “Tipe Penelitian Eksploratif Komunikasi.” Jurnal Studi Komunikasi Dan Media 22 (1): 65-74.

"Pengertian Youtube, Manfaat Dan Fitur-Fitur Menarik Di Youtube." n.d. Accessed October 29, 2021. https://www.jurnalponsel.com/pengertian-youtube-manfaat-dan-fitur-fitur-menarik-diyoutube/.

Safitri, Anggi Aldila. 2021. "Migrasi Televisi Ke Youtube Sebagai Perkembangan Media Teknologi Komunikasi.” Jurnal Teknologi Dan Sistem Informasi Bisnis-JTEKSIS 3 (2): 287-93.

"Variabel Penelitian: Pengertian, Jenis, Dan Contohnya | Kumparan.com." n.d. Accessed November 13, 2021. https://kumparan.com/berita-hari-ini/variabel-penelitian-pengertianjenis-dan-contohnya-1ul9vdTWwAS. 